\title{
Discussion of Merge after Toll in Highway
}

\author{
Jian Liu \\ North China Electric Power University, Baoding 071000, China \\ 903383390@qq.com
}

Keywords: Toll plaza, throughput, cellular Automata model, queue model.

\begin{abstract}
With the development of highways and the soaring of the vehicle numbers, the pressure of transportation is rising constantly. The highway toll plaza where is frequently associated with traffic congestion and accidents greatly influences the travel and transport efficiency. It is urgent to improve the highway efficiency and safety while saving the cost. We use the probability of accidents to reflect accident prevention performance. We discuss the influence of accident prevention between the change of size, shape, and merging pattern of the area.
\end{abstract}

\section{Introduction}

As the per capita car ownership soars, highways initially constructed to mitigate traffic congestion have become increasingly congested. The tollbooth makes the situation worse. The congestion problem still stands even though the popularity of exact-change tollbooths and electronic toll collection booths improve the tollbooth congestion to a certain extent. It has become the aim of many researcher as how to build reasonable toll plazas to satisfy accident prevention and to optimize security of automobiles. For example, Po-Hsing Tseng et al. made a case study in Taiwan to investigate the impact of highway electronic toll collection to the external cost. ${ }^{[2]}$ Muamer Abuzwidah and Mohamed Abdel-Aty compared the traditional mainline toll plaza(TMTP), hybrid mainline toll plaza(HMTP) and all-electronic toll collection(AETC) to assess the safety of the conversion of toll plazas to all-electronic toll collection system. ${ }^{[3]}$ Baiqun Ding et al. Discussed the design calculation of traffic capacity at highway fee collection square. ${ }^{[4]}$ Weiming Liu et al. used the neural network to classify the service level for ETC toll plaza. ${ }^{[5]}$

\section{Accident Prevention Model}

\subsection{The Gradient Rate of Fan-out Area Model}

According to the requirements of safe driving, the enough horizon is needed for motorist in order to ensure the safety at a certain speed. The motorist must have enough judging horizon to realize the dangerous source of information which is difficult to find, then accomplish the driving operation effectively and safely by means of determining risks or its signs of potential to select the appropriate speed and route, and then guarantee safety of themselves in complex traffic environment where is prone to cause visual confusion such as toll plaza.

By the analysis of regression trend,[6][we can get the correlation model of traffic accident and the gradient rate of toll plaza.The specific form of the model as below:

$$
Y_{1}=1.4231 e^{8.0664 x}
$$

Where:

$Y_{1}$ - the value of accident prediction about the gradient rate which is correspond with the toll plaza's export,

$x$ - gradient rate of the toll plaza.

Fitting curve is shown in figure 1. 


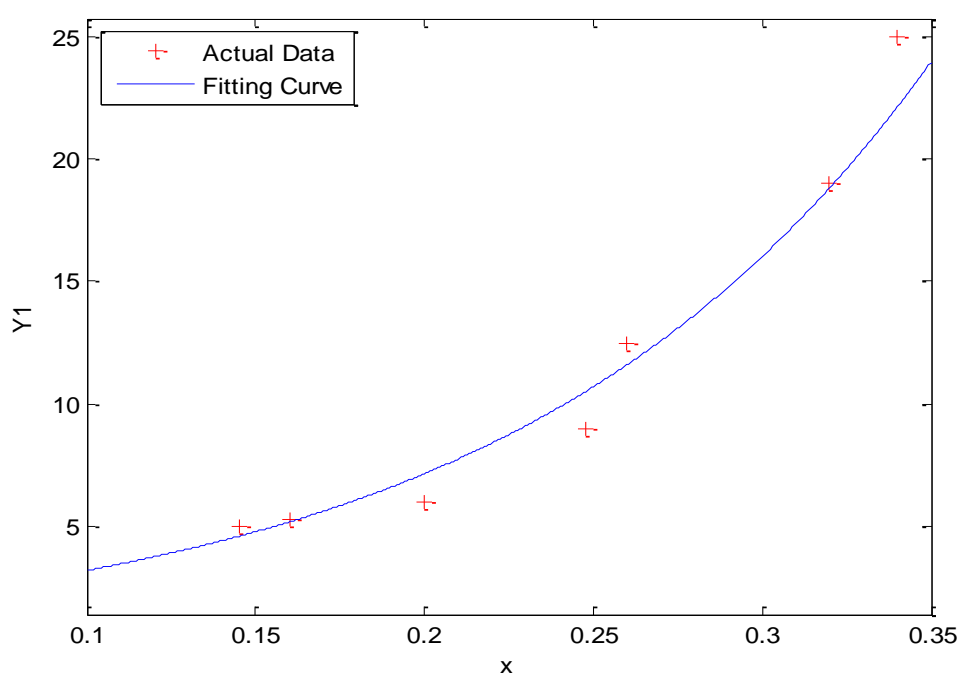

Figure1: the relationship between accident and gradient rate of the toll plaza

Where: $R^{2}=0.8621$.

Through the analysis of correlation curve and correlation model, we can get that the frequency of traffic accident have a direct proportion with the gradient rate of toll plaza on the transition. The gradient rate that exceeds a certain limit will lead to an insufficient gradient length of the transition on the toll plaza's export. That is to say, it will bring about an insufficient visual horizon for judging the vehicles' security, which can not meet the requirements for safety of changing lanes when vehicles pull out the toll plaza.

\subsection{The Profile Grade of Fan-out Area Model}

By the analysis of regression trend, ${ }^{[7]}$ we can get the correlation model of traffic accidents and the profile grade of toll plaza,The specific form of the model as below:

$$
Y_{2}=2.6254 e^{0.638 i}
$$

Where:

$Y_{2}$ - the value of accident prediction about the profile grade which is correspond with the toll plaza's export.

$i$ - the profile grade of the toll plaza's export.

Fitting curve is shown in figure 2.

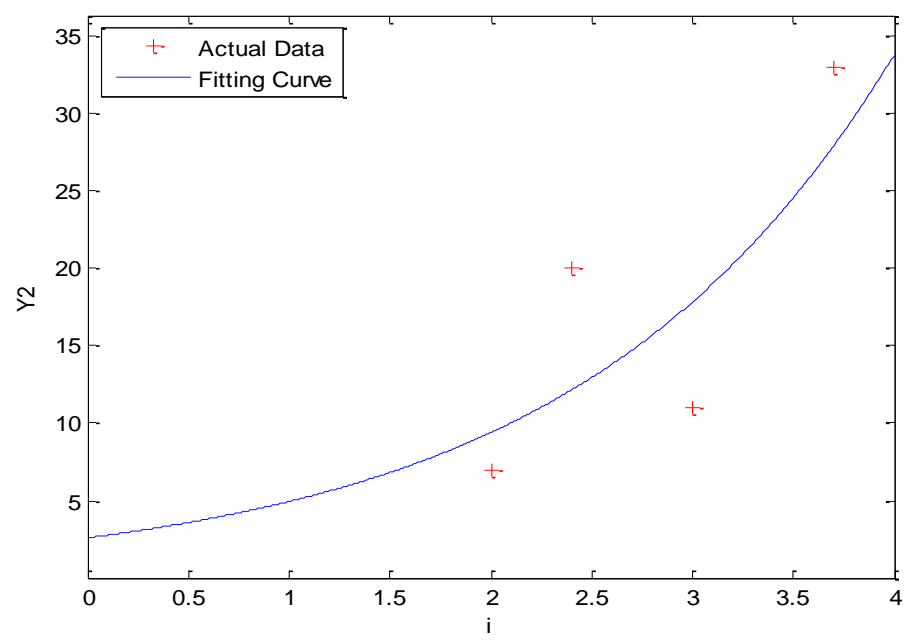

Figure2: the relationship between accident and profile grade of the toll plaza

Where: $R^{2}=0.4219$

In the model, from which we can get that the model has a low correlation. The correlation curve and the correlation model explain that traffic accidents have a direct proportion with profile grade. That is to say, the lower the slope, the greater the performance of safety. 


\subsection{The Merging Pattern in Fan-out Area Model}

By the analysis of regression trend, ${ }^{[8]}$ we can get the correlation model of traffic accidents and the merging pattern in fan-out area, The specific form of the model as below:

$Y_{3}=1624.5 c^{2}-2964.6 c+1357.9$

Where:

$Y_{3}$ - the value of accident prediction about the profile grade which is correspond with the toll plaza's export,

$c$ - the merging pattern in the toll plaza's export $c=B / L$.

Fitting curve is shown in figure 3.

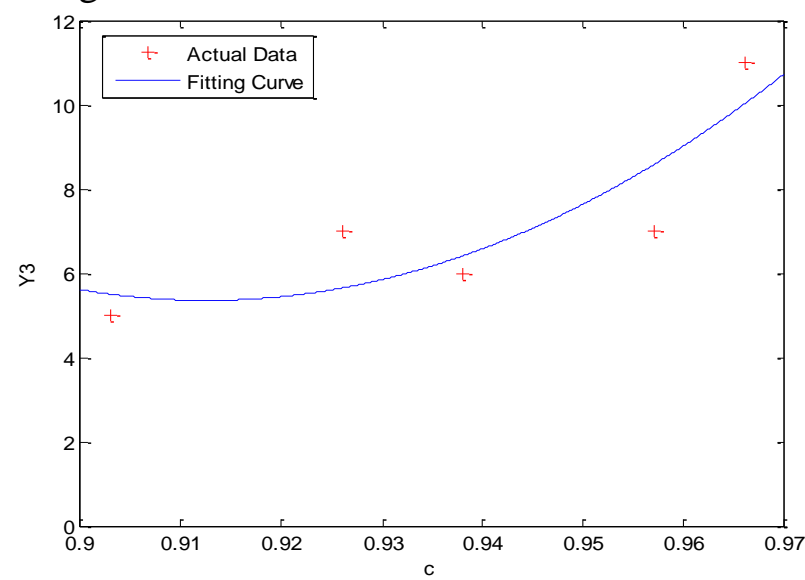

Figure 3. The relationship between accident and merging pattern of the toll plaza

\subsection{Security Model}

The previous analysis explain that there are relationships between the security of toll plaza and shape, size, and merging pattern of fan-out area. Therefore, we should establish a specific relation between security and three factors. The security model as following:

$S=f\left(Y_{1}, Y_{2}, Y_{3}\right)$

Where:

$S$ - the number of traffic accidents in the tollbooth,

By fitting the liner model,we can get the security model as below.

$S=\beta_{0}+\beta_{1} \times Y_{1}+\beta_{2} \times Y_{2}+\beta_{3} \times Y_{3}$

Samples are showed in the matrix as following:

$S=Y \beta$

$$
\boldsymbol{Y}=\left[\begin{array}{ccccc}
1 & Y_{11} & \boldsymbol{Y}_{21} & \cdots & \boldsymbol{Y}_{n 1} \\
1 & Y_{21} & Y_{22} & \cdots & Y_{n 2} \\
1 & Y_{31} & Y_{32} & \cdots & Y_{n 3} \\
1 & \vdots & \vdots & \vdots & \vdots \\
1 & Y_{n 1} & Y_{n 1} & \cdots & Y_{n n}
\end{array}\right]
$$$$
S=\left[\begin{array}{c}
S_{1} \\
S_{2} \\
S_{3} \\
\vdots \\
S_{n}
\end{array}\right]
$$$$
\boldsymbol{\beta}=\left[\begin{array}{c}
\boldsymbol{\beta}_{0} \\
\boldsymbol{\beta}_{1} \\
\boldsymbol{\beta}_{2} \\
\vdots \\
\boldsymbol{\beta}_{n-1}
\end{array}\right]
$$

Where:

$S_{i}$ - the S of sample i,

$Y_{i i}$ - the value of each variable when the sample is $\mathrm{i}$.

Calculate the parameters of each variable $\beta_{0} 、 \beta_{1} 、 \beta_{2}, \cdots \beta_{n}$ by likelihood estimation, we can get a array of regular equations:

$$
Y^{T} S=Y^{T} Y \beta
$$

The maximum likelihood estimation of $\beta$ :

$\hat{\beta}=\left(Y^{T} Y\right)^{-1} Y^{T} S$

The regression model: 


$$
\hat{S}=\hat{\beta}_{0}+\hat{\beta}_{1} \times Y_{1}+\hat{\beta}_{2} \times Y_{2}+\hat{\beta}_{3} \times Y_{3}
$$

After obtaining the regression model, we need do significance tests for linear hypothesis and regression parameters of each variable. Calculating the sum of parameters' squares $S_{e}$, total sum of square $S_{r}$, regression sum of squares $S_{R}$, and then constructing the test statistics:

$$
F=\frac{S_{R} / r}{S_{e} /(n-r-1)}
$$

Where: the rejection region is $F \geq F_{a}(r, n-r-1)$,

$a$-the significance level.

If the value of $\mathrm{F}$ is in the domain of rejection region when the significance level meets the requirements, which will explain the founding linear hypothesis and the significant effect of curve regression.

\section{Conclusion}

With the development of highways and the soaring of the vehicle numbers, the pressure of transportation is rising constantly. The highway toll plaza where is frequently associated with traffic congestion and accidents greatly influences the travel and transport efficiency. It is urgent to improve the highway efficiency and safety while saving the cost. We use the probability of accidents to reflect accident prevention performance. We discuss the influence of accident prevention between the change of size, shape, and merging pattern of the area.

\section{References}

[1]. Information on: https://en.wikipedia.org/wiki/Lincoln_Highway

[2]. Po-Hsing Tseng, Dung-Ying Lin, Steven Chien, Investigating the impact of highway of electronic toll collection to the external cost: A case study in Taiwan, Technological Forecast \& Social Change, 11 November 2013.

[3]. Muamer Abuzwidah, Mohamed Abdel-Aty, Safety assessment of the conversion of toll plaza to all-electronic toll collection system, Accident Analysis and Prevention, 21 April 2015.

[4]. Baili Wang, Xiaofeng Yang, Hongxing Liu, Lane-Changing Behavior Simulation Research in Traffic Merging Area, Computer Simulation, (33)2: February 2016.

[5]. Weiming Liu, Liping Guan, Xiangyuan Yin, Method of service level classification for ETC toll plaza based on neural network, Journal of Traffic and Transportation Engineering, (3)3: September 2003.

[6]. Li Sun, Study on the design of highway toll station, April 2012. 